\title{
A Study of the Morphological and Histological Structure of the Caudal Fin of the Female Swordtail Fish Xiphophorus helleri and the Effect of Hydrocortisone on it
}

\author{
Muneerah A. Ibrahim Ali A. Al-Ali* \\ Dept. of Biology / College of Education for Pure Science / University of Basrah
}

\begin{abstract}
The caudal fin is one of the most important types of fins used in the movement of fish and is important in studying the effect of various factors on bone, especially medicines and drugs. The females of the Xiphophorus helleri were obtained from aquarium fish shops. The mature females were divided into two groups, each containing 14 fish, placed in 60 liter glass aquarium, the first group treated as control group, while the second group was treated with Hydrocortisone Sodium Succinate (Roxcortisone) with a concentration of $2.5 \mathrm{mg} / 1$. After a month of experimentation, the samples were fixed by a Formalin $10 \%$ in order to prepare them for the whole-mount loading method and the normal tissue sections. The results of the phenotypic study of the caudal fins of female $X$. heller $i$ showed that they consist of three types of fin rays, which are unsegmented and unbranched, segmented and unbranched, and segmented and branched. These three types differ in terms of shape and structure, as histological structures showed that the first type rays, i.e. unsegmented and unbranched, and the first ray of the second type, i.e. segmented and unbranched, have pear shaped. The cavity between the two halves of rays is filled with connective and neural tissue, while the other rays of second type have a heart shape and filled with muscle tissue. The shape of the third type, i.e. segmented and branched, varies depending on their location in the fin. The results of the study of morphological of the caudal fin of females treated with hydrocortisone showed that there was an irregularity in the fin rays in general, which led to a difference in the branching positions of the branched rays compared to the control group. It was also noticed that there was a fusion in the rays composing the fin and another fusion of internodes composing the one fin in comparison to control group.
\end{abstract}

Keywords: Xiphophorus helleri, caudal fin ,fin rays ,hydrocortisone hormone

DOI: $10.7176 / \mathrm{JNSR} / 9-4-06$

\section{Introduction}

Fins are one of the extensions of the lateral structural system, and their shape and composition vary according to the types of fish, in addition to their differences in number and location. Fins are either paired which include pectoral and pelvic, or unpaired, which are the dorsal, anal and the caudal, as well as the adipose fin, which is found in the fish of the family Salmonidae and Ictaluridae (Spurny, 1998; Baruš and Oliva, 1995).

The fins play an important role in the movement of fish, obtaining food, and escape from prey, especially the caudal fin, which works to equip the fish with the force needed to propel it forward, as well as to work as breaks in cooperation with the pectoral fins(Lauder and Drucker, 2004; Drucker and Lauder, 2003).

Fins in bony fish are generally epidermis structures consisting of bone rays called Lepidotrichia and a thin collagen membrane that binds rays to each other (Lauder, 2006). Each bony ray consists of a pair of long convex in two halves or parts, each member of this pair is called Hemitrichia, they appear connected to each other at the base of the fin only. Hemitrichia is longitudinally divided into a number of pieces called Lepidotrichia hemisegens, which are separated by fixed joints called Joints (Arita, 1971). Extending from the far end of each bony ray to the outer edge of the fins are a group of small, thin spindle called Actinotrichia which in turn support the membrane tip of the fin (Krukenberg, 1985; Becerra et al., 1983).

Many substances, such as hormones, medicines, drugs, and heavy metals generally affect fins both in terms of appearance or regeneration or repair. The regeneration of fins in some bone fish is weak when treated with Dexamethasone (Bechara et al. 2000). By treating Cyprinus carpio fish with Dexamethasone at $20 \mathrm{mg} / \mathrm{L}$ concentration for 10 days following the cut-off of the fin, Ochandio et al. (2015) found that there was a slow process of re-generation of Lepidotrichia.

Kumar et al. (2016) clarified that the immersion of Betta splendens larvae in three different concentrations $(100,250$ and $500 \mathrm{mg} / \mathrm{L})$ of the hormone $17 \alpha$ - Methyltestosterone three hours per day for 21 days causes shortening in the length of all types of larval fins compared to the control group.

Some medicines and heavy metals affect the re-generation of different fins. Bechara et al. (2003) found that there was no regeneration of actinotrichia when treating Tilapia rendalli with Acetylsalicylic acid (Aspirin) (0.1 g ( L) after cutting the caudal fin $3 \mathrm{~mm}$ from Muscular peduncle for 12 days.

Atta et al. (2012) discovered that the treatment of Oreochromis niloticus with heavy metals such as lead, cadmium and mercury affect the structure of Blastema cells during the re-generation of the caudal fin. A trophy of the nucleus of Blastema cells, a hardening mitochondrial glands and the degeneration their in cytoplasm was 
observed.

Due to the lack of morphological studies of the fins of Xiphophorus helleri in general and the importance of caudal fin in the study of the action or effect of medicines and drugs on bone, the present study aimed to examine the morphological structure of the caudal fin of $X$. helleri and the effect of hydrocortisone on it.

\section{Materials and Methods}

\section{Providing Fish Samples and Breeding them}

The mature females of Xiphophorus helleri, weighing $2.3 \mathrm{~g}$, were obtained from the aquarium fish shops in Basrah Governorate and transferred to the Chamber of Animal Husbandry at the Animal House of Department of Biology / Colleg of Education for Pure Sciences by oxygenated plastic bags. The fish were then placed in glass aquariums (200 liter) filled with RO water, equipped with continuous water ventilators by air pump and waste and residue purifiers. The fish in aquarium exposed to lighting 11 hours, salinity $(0.892 \mathrm{PPT})$ and temperature $\left(28-25^{\circ} \mathrm{C}\right)$. The fish were then fed mixed leafy vegetables (vegetarian-animal) and dried worms.

\section{Treatment with the Hydrocortisone Hormone}

The mature fish females were divided into two groups each containing 14 fish, placed in 60 liter glass aquariums equipped with continuous ventilation. The first group was treated as a control group, while the second group was treated with the Hydrocortisone (Roxcortisone) Sodium Succinate manufactured in Netherlands (with a concentration of $2.5 \mathrm{mg} / 1$ ) (Mazloumi et al., 2015) by dissolving the hormone in water.

The water was completely changed every 48 hours in order to maintain the effectiveness of the hormone. After a month of experimentation, the samples were fixed by Formalin $10 \%$ by 4 replicates per group, the last quarter of the fish body, including the caudal fin, was cut to prepare for the whole-mount staining and normal tissue sections.

\section{Whole-mount Staining}

For the whole-mount staining, Darias et al. (2010) method was adopted. The samples were washed with tap water for 24 hours to remove the fixer. They were then placed in whitening solution of Potassium Hydroxide $(\mathrm{KOH})$ concentration of $2 \%$ and Hydrogen Peroxide concentration of $3 \%$ for 7 days until all dark spots disappeared and the sample color became yellowish. They were transferred to the Alcian Blue stain solution for 24 hours, then placed in distilled water for 2-3 hours to remove the excess stain.

The samples were transferred to the Trypsin solution (1/4 teaspoon per $100 \mathrm{ml}$ of Enzyme buffer) for 3-4 weeks until they became transparent so their bones were clearly visible to the naked eye. They were then placed in the Alizarin red stain for 5 hours and then washed with Potassium Hydroxide $\mathrm{KOH}(2 \%)$ to remove excess stain. They were passed through progressive serial concentrations of Glycerin and Potassium Hydroxide $\mathrm{KOH}(2 \%)$,concentration (30\%) (30ml of Glycerin and 70ml KOH(2\%)), concentration (60\%) (60ml of Glycerin and $40 \mathrm{ml} \mathrm{KOH}(2 \%))$ and concentration $(90 \%)(90 \mathrm{ml}$ of Glycerin and $10 \mathrm{ml} \mathrm{KOH}(2 \%))$ for 24 hours per concentration till reaching the absolute glycerin in which they were stored. The samples were then examined and photographed using a composite imaging microscope Leica type and Digital Microscope.

\section{Preparation of Histological Sections}

The normal histological sections were prepared using Humason(1972) method. Before the paraffin waxing was done, the samples were washed with tap water for 12 hours to remove the fixer and then stored with an ethyl alcohol concentration of $70 \%$. The process was then completed by passing the samples through a progressive concentration of $80 \%$ and $\% 90$ of ethyl alcohol for an hour for each concentration with switching and $100 \%$ for five hours with every hour switching. The samples were then cleared using the xylene for 10 minutes. They were then transferred to the melted paraffin wax in an electric oven of $60 \mathrm{C}^{\circ}$ for 5 hours. After that, they were embedded in a pure melted wax using suitable copper molds.

After cutting the wax molds containing the samples, they were treated using rotary microtome to cut the samples with a thickness of 7 micrometers and then transferred to the water bath. The temperature ranged from $45-40 \mathrm{C}^{\circ}$ to allow the sections to be stretched and flattened and then loaded onto clean glass slides. The sections were then pigmented with the eosin and hematoxylin. They were then examined and photographed by the Leica composite imaging microscope.

\section{Results}

\section{The Morphological Structure of the Caudal Fin}

The results of the morphological study of the caudal fins of $X$. helleri's showed that these fins were homocercal, almost rounded (Picture 1), asymmetrical, 31-29 of the Lepidotrichia fin ray. The number of rays in the dorsal half was less than in the ventral half. It was observed that the caudal fin rays appear in three types, so that they can be distinguished depending on the shape and length of the rays which are closely related to the location of that ray on 
the caudal fin(Picture 2).

\section{Unsegmented and Unbranched Rays}

This type of rays is located at the upper edge of the dorsal side and the lower edge of the ventral area of the caudal fin. The number of these rays is four and distributed evenly on each side (a pair on each side). They are characterized by being of one unsegmented and unbranched piece and are the shortest of caudal fin rays. The rays of each pair vary in length: the rays at the far outer edge of the dorsal and ventral region are shorter than those of the pair inside (Picture 3).

\section{Segmented and Unbranched Rays}

Following the rays of this type are those of the first type directly, ranging between 12-11 rays distributed unevenly, $7-6$ on the ventral side, and 5 on the dorsal side of the caudal fin. These rays are longer than the first type, and are graded in length: the shortest are those near the first type rays. They are made up of one beam divided into a number of pieces, each of which is called an internode. The number of these internodes varies. The number of internodes forming the one ray decreases when approaching the base of fin, so that the rays closer to the first type of both dorsal and ventral contain the smallest number of pieces (Picture 4).

\section{Segmented and Branched Rays}

The rays of this type are the longest caudal fin rays, and occupy the center of the fin between the rays of the second type from the dorsal and ventral sides, thus representing the middle section of the fin. Their number is $15-14$ rays that are approximately equal length, and each branch into two sections at its distal end. The branching points are affected by the length of fin rays, so the branching points draw a default parenthesis that roughly corresponds to the end edge of the side of fin. It was noted that these branches appear to different degrees with Alizarin and Alcian blue depending on the parts of these branches: with Alizarin in the near part, they appear in a pale color that gradually disappears as we move towards the distant part to begin colored in Alcian blue (Picture 5).The beam of these rays are divided into a number of joint internodes separated from each other by the joint. In the middle part of ray, the internodes are square shape (Picture 6) and then elongated as they move towards the distant end of the ray (Picture 7). Each branch ends with small soft prickles that are Actinotrichia (Figure 8). 


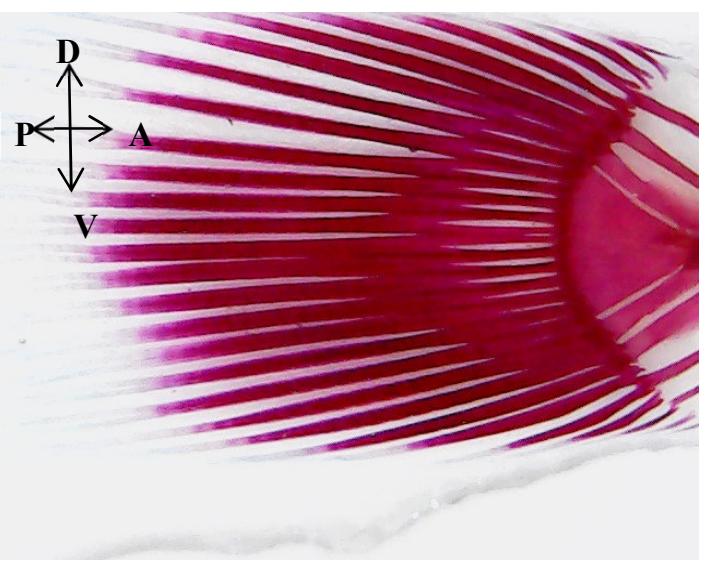

Picture ( 2) : A picture of the caudal fin of the $X$. helleri, illustrating the fin ray types, $D$ (dorsal), $\mathrm{V}$ (ventral), A (anterior), $\mathbf{P}$ (posterior) whole mount, 40x.

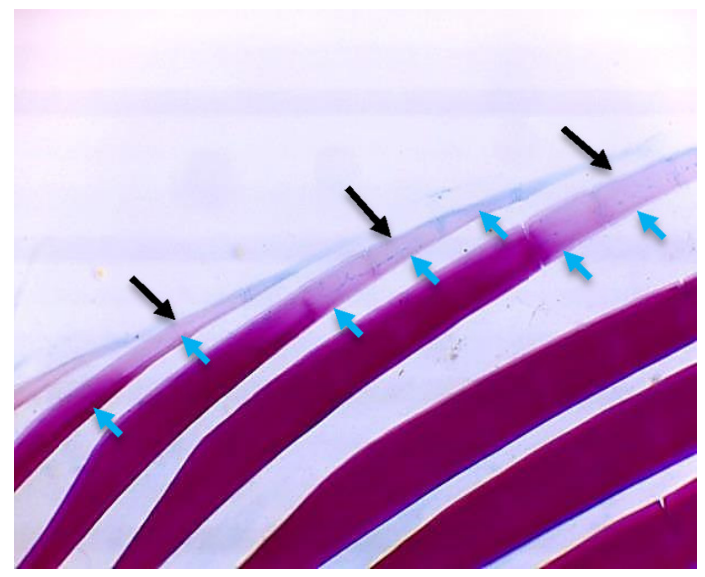

Picture (4) : Segmented and unbracnched rays of the caudal fin (large arrows), showing the gradient in length, and the division of the rays into pieces which called (internodes) (small arrows), whole mounts, $40 x$.

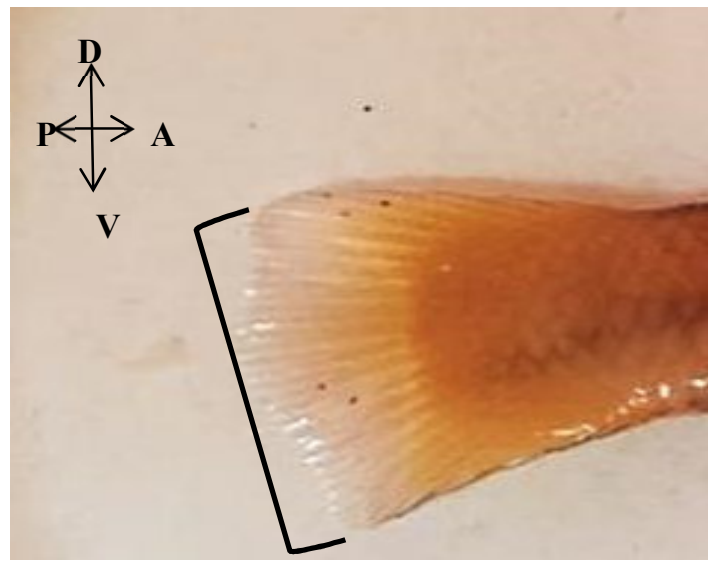

Picture (1): A picture of the caudal fin of the $X$.helleri fish, note the fin type, D (dorsal), $\mathrm{V}$ (ventral), A (anterior), P (posterior.

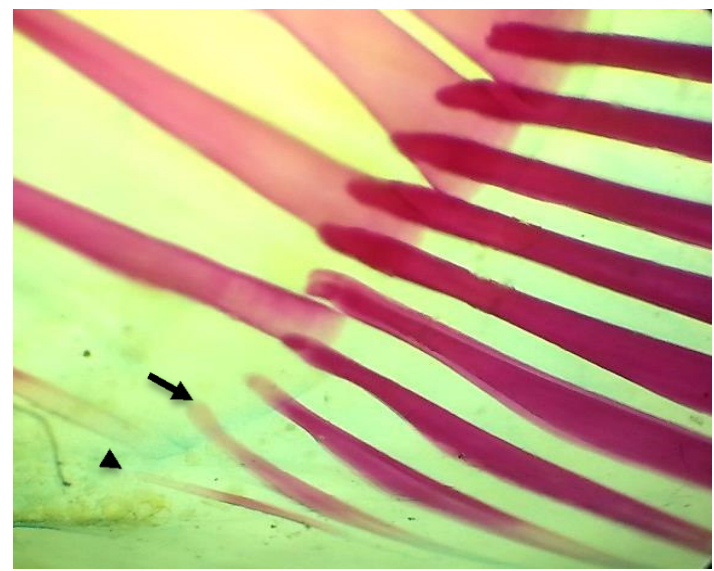

Picture (3): Unsegmented and unbracnched rays of the caudal fins, the ray that appear outside (arrowhead) are shorter than the ray inside them (arrow), whole mount, 40x. 

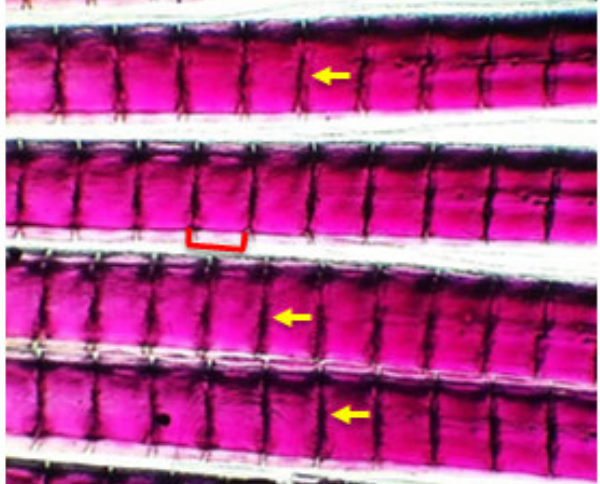

Picture ( 6) : Segmented and branched rays of the caudal fin, showing the internodes of the central part of the rays square shape $(\operatorname{arch})$. Note the presence of the joint between the internodes (arrows) whole mounts, $40 x$.

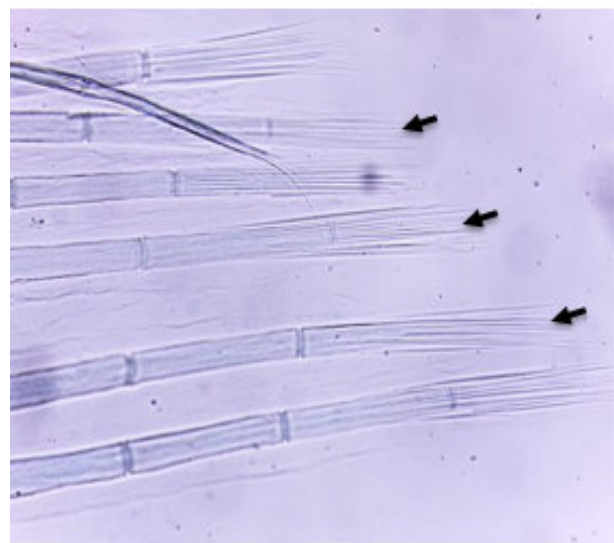

Picture (8): Actinotrichia structures (arrows) at the end of rays the whole mount, 100x.

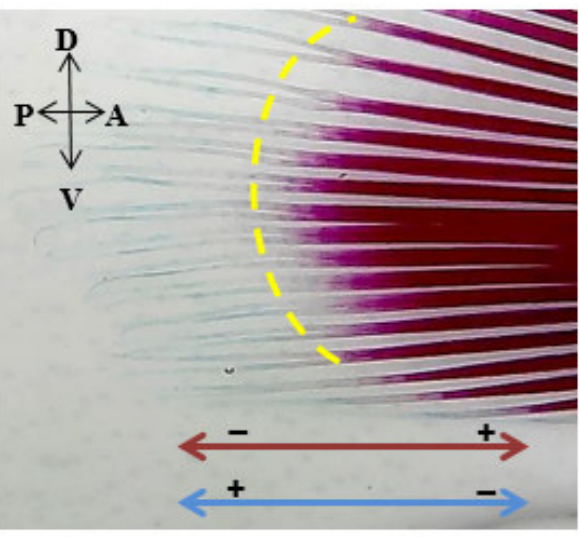

Picture (5) : Segmented and branched rays of the caudal fin, showing the split of rays into two branches and the points of the emergence of the branch (intermittent arc). Note the gradient with the Alizarin pigment (purple arrow), the Alcian blue(blue arrow), $\mathbf{D}$ (dorsal), $\mathbf{V}$ (ventral), A (anterior), $P$ (posterior), the whole mount, the $40 x$.

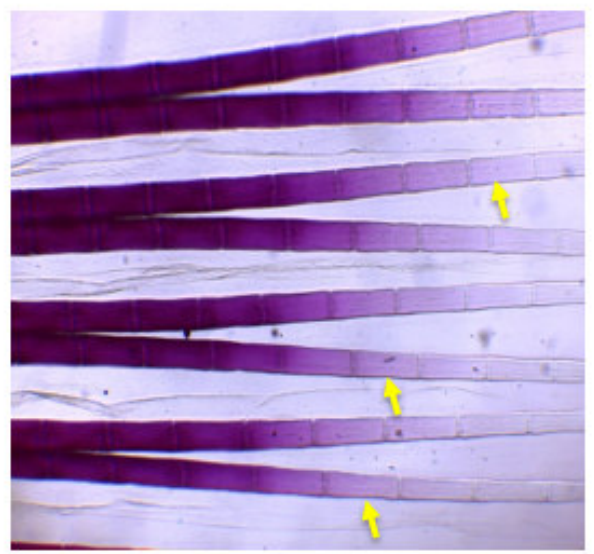

Picture (7) : Segmented and branched rays of the caudal fins, showing elongation of the internodes (arrows) at distal part of the rays, whole mount, 40x.

\section{Histological Structure of the Caudal Fin}

The results of the histological sections showed a difference in the shape and histological structure of the fin rays, depending on the type of rays and the position of the fin. As for shape, pyriform was identified in the first type rays(unsegmented and unbrached) and some rays of the second type. The two halves of rays are close to each other at the middle line of the fin (Picture 9A), while the second type rays appeared almost cordate and their size increase when moving towards the midline of the fin (Picture 9B). The third type (segmented and branched) rays differ in their shape depending on their location in the fin. In the base part of the caudal fin, the two halves of this type appear in the shape of a bony hard rod (Picture 9C) and then these two rods start to concave as they turn towards the middle part of the fin (Picture 9D) until they become a curved bone plate near the far end of the fin (Picture 9 E).

As for the histological structure, it was found that all types of caudal fin rays contain nerve tissue in a very small area of the site adjacent to the bone tissue from the internal surface of the ray (in the area of concavity). Most of the cavity located between the two halves of rays is muscular tissue (Picture 9B, C) except for the posterior cavity of the fin (dorsal and ventral) which are 4 in number: two are unsegmented and unbranched and the other two are segmented and unbranched, their cavity is filled with connective and neural tissue (Picture 9 A, B). 


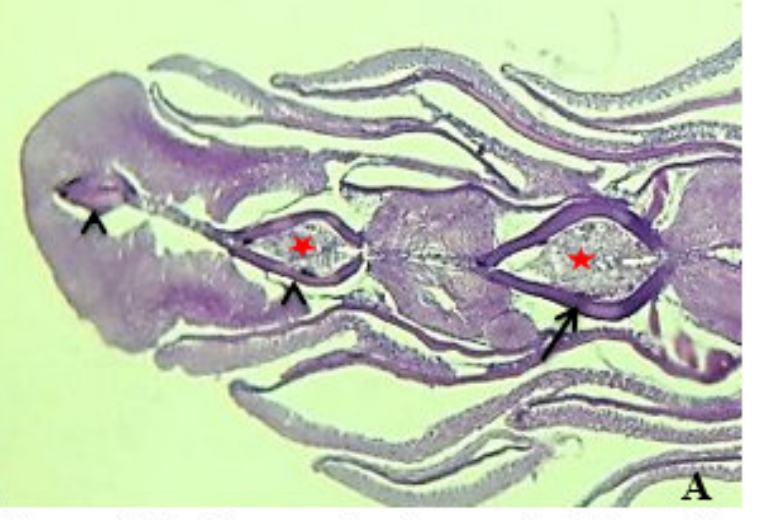

Picture (9A): Cross-section in area $A$ of Photo (9) shows the shape and structure of the unsegmented and unbranched (arrowheads). In this section, are showed the first fin rays of the segmented and unbranched (arrow). See the shape of rays in the section of the two types seems pyriform and cavity is filled with connective and neural tissue (stars), H \& E, stain, 100x.

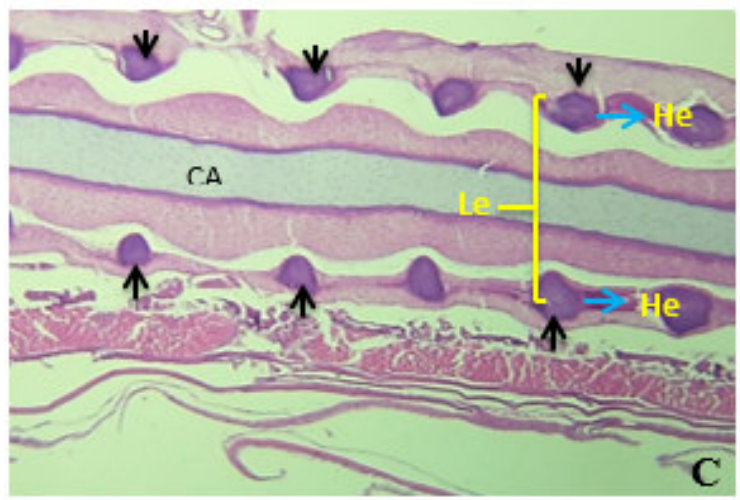

Picture (9C): Cross-section in the base of the caudal fin showing the two halves of the rays which are segmented and branched in the shape of a hard bone rod, (small arrows), cartilage $\mathbf{C A}$, Lepidotrichia (Le)(arc), Hemitrichia (He), H \& E stain, 100x.

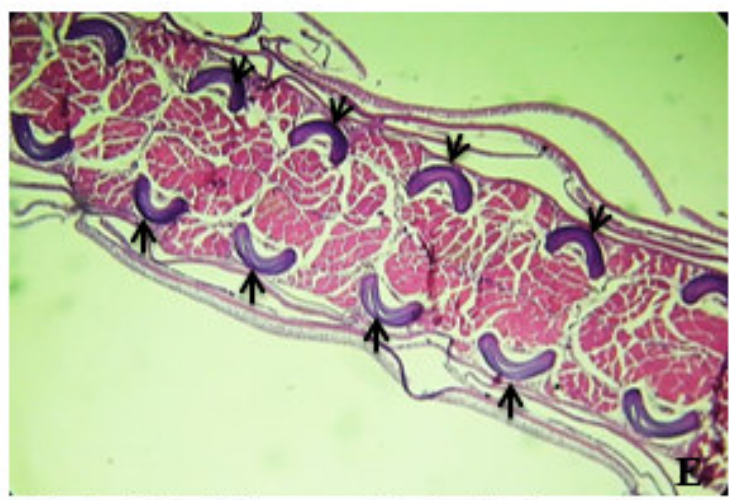

Picture (9E): A Cross-section in the far end of the caudal fin, showing the two halves of segmented and branched fins in curved bony plates ( small arrows), H \& E stain, 100x.

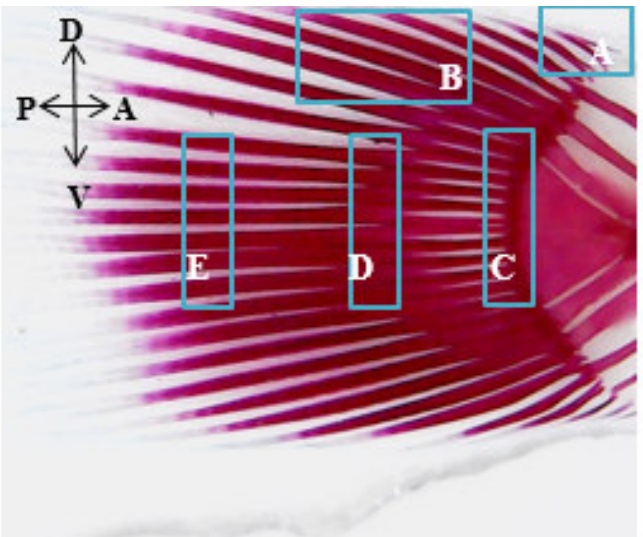

Picture (9): Whole mount of the caudal fin, A, B, C and D show the caudal fin rays a digital microscope, $\mathrm{D}$ (dorsal), $\mathrm{V}$ (ventral), A (anterior), $\mathrm{P}$ (posterior), 40x.

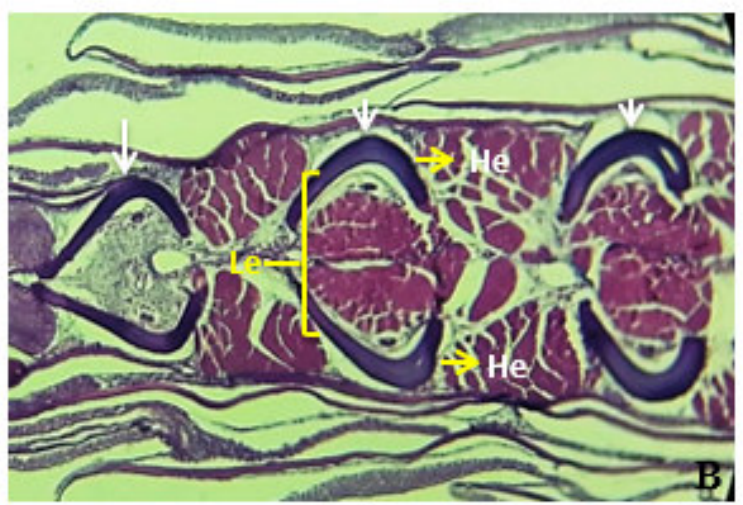

Picture (9B) : A cross section of the caudal fin showing segmented and unbranched which are cordate in shape, filled with muscle tissue (Small arrows), except for the second fin-rays of this type, whose cavity is filled with connective and neural tissue (arrow), Lepidotrichia (Le), (He) Hemitrichia, H \& E stain, 100x.

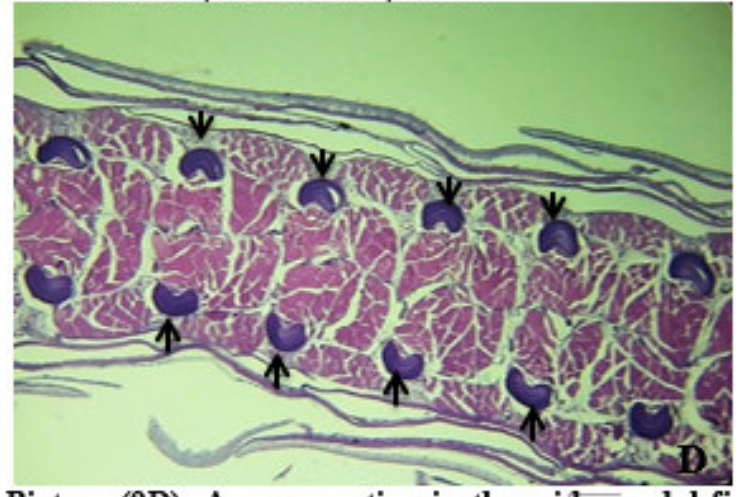

Picture (9D): A cross-section in the mid-caudal fin showing the appearance of concave in the two halves of the segmented and branched fins, (arrow heads), $\mathrm{H}$ \& $\mathrm{E}$ stain, $100 \mathrm{x}$. 
Effect of Hydrocortisone Hormone on the Morphological Structure of the Caudal fin

The morpholoical study of the caudal fin of $X$. helleri treated with hydrocortisone showed that the morphology of the fin was irregular (Picture 10), due to the difference in the lengths of the one type of fin-ray, i.e. dorsal, ventral or middle (Picture 11) compared to the control group. The results of the microscopic examination showed that the longest rays were the rays located in the central area of the caudal fin, which included some of the second type (segmented and unbranched) rays and the third type (segmented and branched) rays, which are located near the second type (Picture 11).

It was observed by microscopic examination that there is a difference in the locations of the branching points of the third type (segmented and branched) of the treated caudal fin. The branching points appeared at different distances of the ray (Picture 13) compared to those in the control group, which were at one level (Picture 14).

The results of the microscopic examination showed a secondary branching of the primary branches of the third type (segmented and branched) of the caudal fin. The number of branches constituting the primary branch varies. The primary two branches may be divided into two secondary sub-sections (Picture 15) or one of the primary branches is split into two secondary branches and the other not (Picture 16).

A longitudinal merging between the primary two branches of two adjacent branches of the third type of the caudal fin was observed. This merger begins from the branching area of the two branches and extends to a distance. The secondary branches are separated from each other to move in a parallel line (Picture 17). A fusion among the internodes related to the same ray was also noticed. This fusion was either partial from one of the upper or lower sides of the internodes (Picture 18), or full between the internodes (Picture19).

The results of the microscopic examination showed that the fracture treatment process was originally performed in different regions of the caudal fin, whether in the proximal, central or distal area of the fin, which appeared as burls in the third type of rays and at different distances (Picture 20, 21 and 22). 


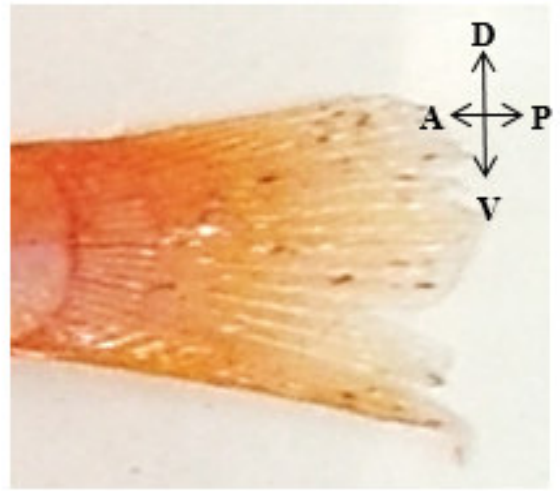

Picture (10): A picture of the caudal fin of $X$. helleri showing the treatment with hydrocortisone, D (dorsal), V (ventral), A (anterior), P (posterior).

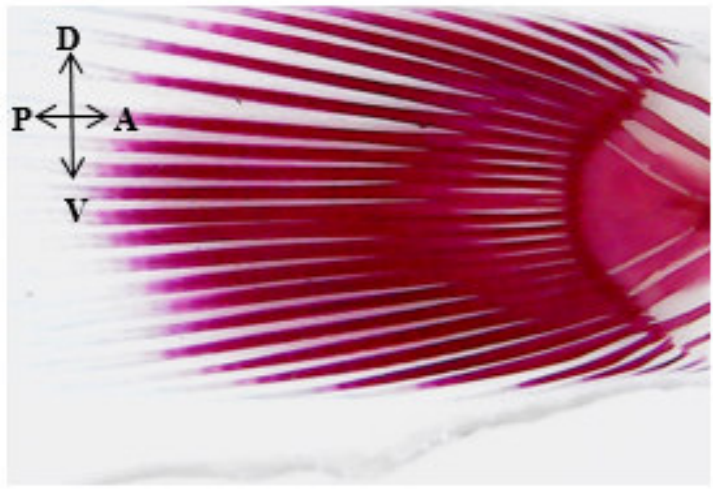

Picture (12): The caudal fin of the $X$. helleri control, showing the fineness of the fin rays in their lengths $\mathrm{D}$ (dorsal), $\mathrm{V}$ (ventral), $\mathrm{A}$ (anterior), $P$ (posterior), whole mount $40 x$ digital microscope.

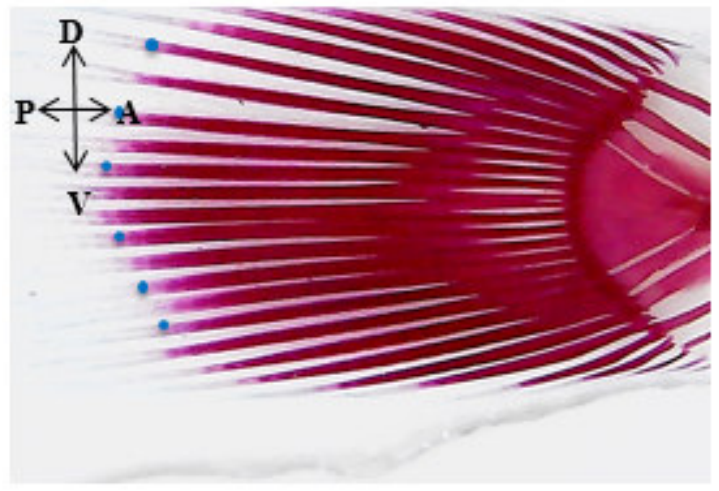

Picture (14) : The caudal fin of the $X$. helleri control, showing the regularity of the points of branching in the third type (spots), D (dorsal), $\mathrm{V}$ (ventral), $\mathrm{A}$ (anterior), $\mathbf{P}$ (posterior), whole mount, 40x digital microscope.

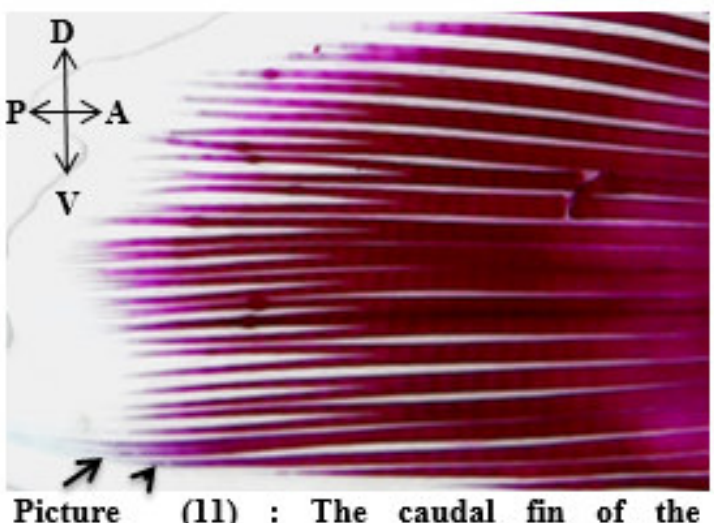

hydrocortisone-treated $X$. helleri, showing the difference in the length of the fin rays in general. The second type (arrowhead) and the third type (arrow) rays are longer than the rest of the rays, $D$ (dorsal), $V$ (ventral), $A$ (anterior), $\mathbf{P}$ (posterior) whole mount, 50x digital microscope.

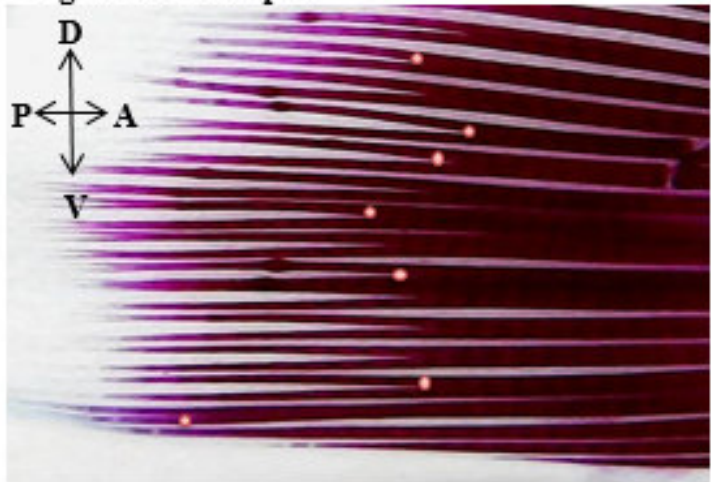

Picture (13): The caudal fin of the $X$. helleri treated with hydrocortisone, showing the difference in the locations of branching in the third type (spots), D (dorsal), V (ventral), A (anterior), $\mathbf{P}$ (posterior) whole mount, 50x digital microscope. 


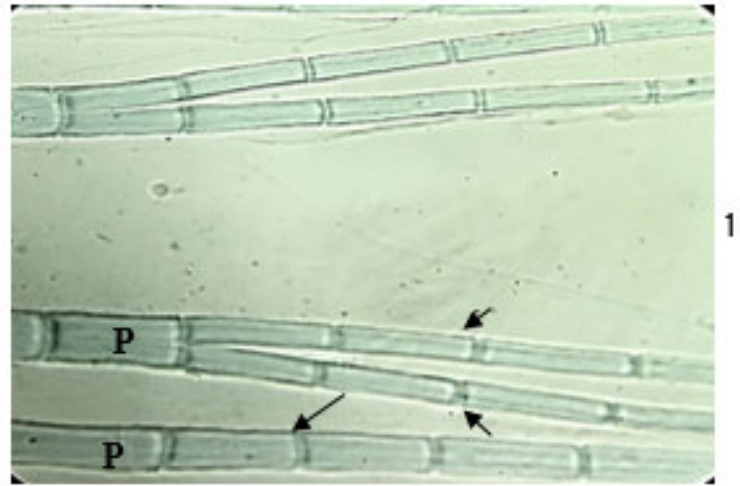

Picture (16): The caudal fin of the hydrocortisone-treated $X$. helleri, showing the branch of one of the primary branches (P) to two branches (small arrows) while the other primary branch of the third type (big arrow) whole mount, $100 x$.

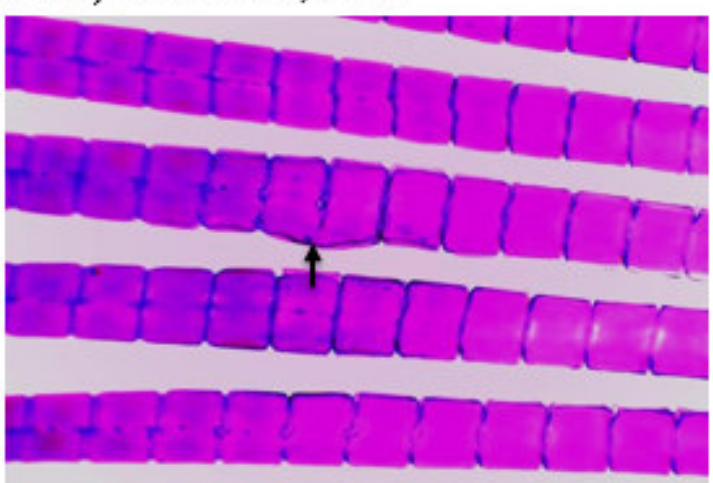

Picture (18) : The caudal fin of the hydrocortisone -treated $X$. helleri, showing a partial fusion between two adjacent internodes(arrow), whole mounts, 40x.

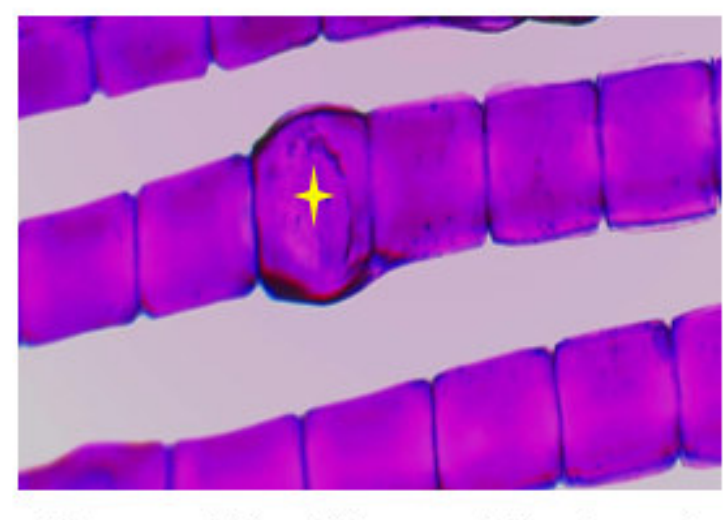

Picture (20): The caudal fin of hydrocortisone-treated $X$. helleri, showing the occurrence of a fracture treatment (repair) in one of the internodes of fin rays (star) in the area near the base, whole mount, 40x.

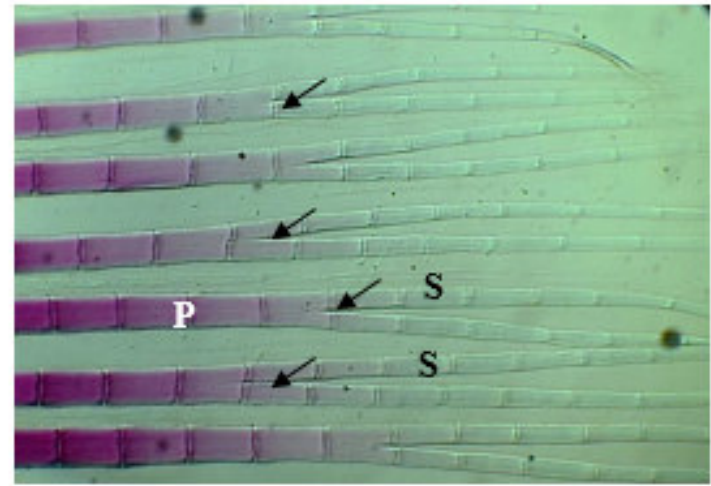

Picture ( 15) : The caudal fin of the hydrocortisone -treated $X$. helleri, showing the occurrence of a secondary branch (S) at the end of the primary branches $(P)$ of the third type ray(arrows), the whole mount, a 50x digital microscope.

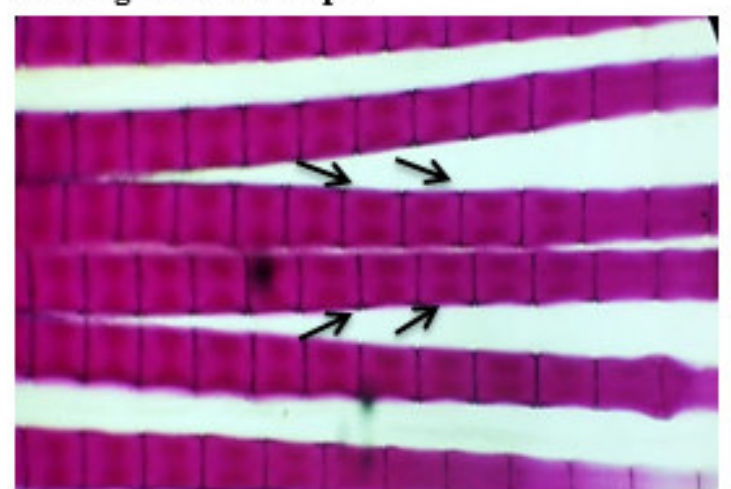

Picture (17): The caudal fin of the hydrocortisone -treated $X$. helleri, showing the occurrence of a fusion between the primary two branches of two adjacent rays of the third type (arrows), whole mounts, 40x.

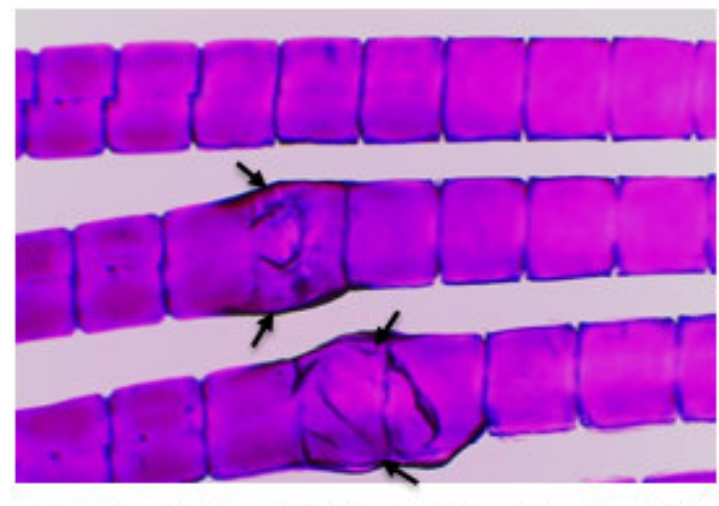

Picture (19) : The caudal fin of the hydrocortisone -treated $X$. helleri, showing a full fusion between two adjacent internodes (arrows) whole mounts, $40 x$. 


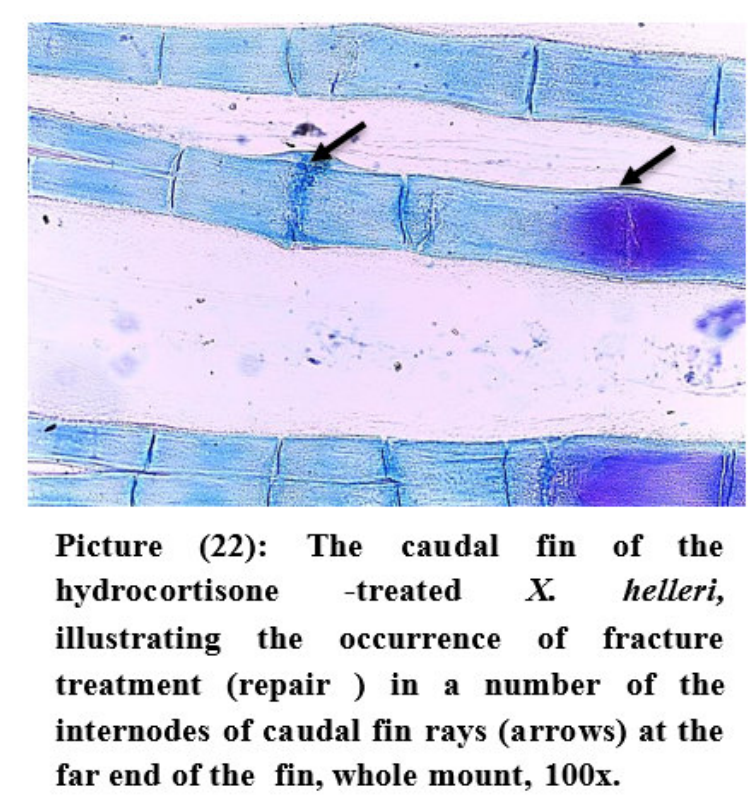

15

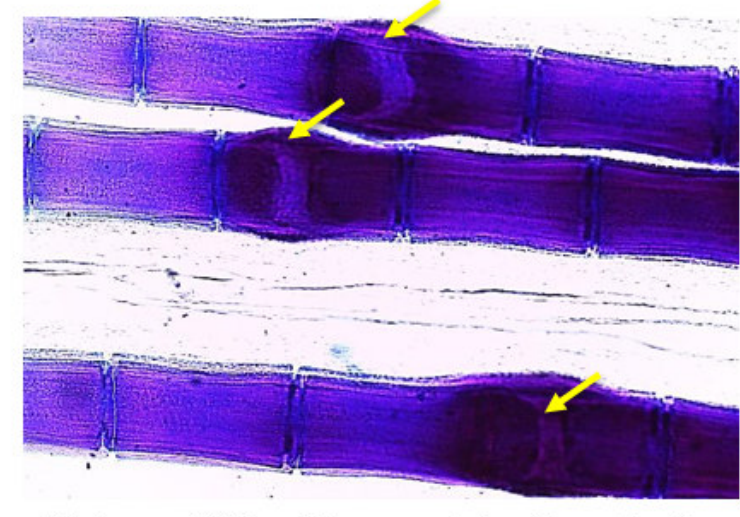

Picture (21): The caudal fin of the hydrocortisone -treated $X$. helleri, illustrating the occurrence of fracture treatment (repair) in a number of the internodes of fin rays (arrows) in the central region of the caudal fin, whole mount, 100x.

\section{Discussion}

The correlation of caudal fin in bone fish generally depends on the number of segmented and unbranched rays of the dorsal and ventral region of the fin. The caudal fin is secondary symmetrical when the fin contains an equal number of segmented and unbranched dorsal and ventral rays as in the Draculo species. While the caudal fin is asymmetric if the number of segmented and unbranched rays is not equal in both dorsal and ventral sides, as in Callionymid fish, which has one dorsal segmented and unbranched ray and two ventral (Fricke, 1981a, b). $X$. helleri has seven to six venral segmented and unbranched rays and five in the dorsal region, which means that it is classified as an asymmetric fin.

The shape of the fin varies depending on the fish type ,in the fish under study, the fin is circular in shape, while as a simple tube in Eels, a disk in the Angel fish or hammer head as in Sharks. The shape also varies according the length of rays, where the fin of the Zebrafish is a biloba and has a paddle shape in the American minnow and an elaborate sword as in the male of Xiphophorus (Johnson and Bennett, 1999).

The reason of difference in shape and structure of caudal fin in fish may dependent on particular habitat and swimming speed for escape from a dangerous situation or for hunting living organisms. Thus fish may have evolved specific adaptations such as various fin shapes that were suitable for their particular habitat or biological reasons(Sfakiotakis et al., 1999).

The main components of the caudal fin of X.helleri are generally similar to those of fins in most bone fish (Akimenko et al., 2003; Mabee et al., 2002), with the exception of some differences in the number of rays, types and their branches that distinguish fish populations from one another. This is demonstrated by the results of the present study of $X$. helleri, where the fin is composed of 7-6 of the segmented and branched rays in the ventral region, 5 of them in the dorsal side, and 15-14 are dual-branching. We have found that this pattern of distributing caudal fin rays is similar to the pattern of Callionymid, except the number of rays: it consists of one dorsal fin segmented and branched rays, two ventral and seven dual-branching central rays (Fricke, 1981b).

The difference in discoloration of parts of the fin segmented and branched ray branches stained with the dual Alizarin-Alcian blue may indicate incomplete maturity or growth of the branches, especially those located at the far end of the ray, which are characterized by their acceptance of the Alcian blue stain. As it is known, in those parts of bone which accept this stain, the concentration of calcium is little and mineralization process is incomplete, i.e. they are still in the cartilage phase, which proves that the process of growth of caudal fin rays occurs by adding new internodes to the far end of the rays and not through the increase in the length of one internode (Bennett, 1999 ).

The difference in the location of branching points in the hydrocortisone-treated caudal fins of $X$. helleri is attributed to the irregular growth of the fin rays as a result of a disturbance in the growth process, making the branching points take different positions compared to the control group. This may be due to the effect of corticosteroids on the construction and degradation of collagen fibers. Dexamethasone deformity in the skin of mice was found to be due to the breakdown of collagen fibers Type I and III (Oishi et al., 2002) in addition to inhibiting the responsible cells to build collagen by discouraging the translation of mRNA of collagen Type II (Kaweshimg et al., 2003). 
This explains why fusion between the branches of the caudal fin rays and the fusion between halves in one ray takes places. That is to say, it occurs as a result of the effect of hydrocortisone used in the current study on the process of building collagen fiber in general, and those that fall between the rays of the fin and places of joints between pieces of rays in particular.

Glucocorticoid causes osteoporosis, which results in a decrease in bone mass and an increase its absorption (Fitzpatrick, 2006). The effect of cortical hormones on bone absorption appear in the increase of the RANK-L factor in Osteoblast bone cells (1999), as well as its effect on the programmed death of bone-construction cells (Liu et al. 2004) and osteoporotic cells in mature bones. All of these factors lead to an increase in the number of bone dissociating cells more than usual, which increases the risk of bone fractures due to long-term bone absorption associated with osteoporosis caused by cortical hormones (Kim et al., 2006; Weinstein et al, 2002).

This is confirmed by the current study by observing the occurrence of multiple fractures of the caudal fins in different locations as a result of the effect of the hydrocortisone hormone on the fin, making it weak and fragile. Although the fish under study are repairing the fractures of the fin and the re-generation of bone under the influence of hydrocortisone, now this process produces abnormal growth of bone (Tolar et al., 2004)

\section{References}

Akimenko, MA.; MarÍ-Beffa, M.; Becerra, J. and Géraudie, J.(2003). Old questions, new tools, and some answers to the mystery of fin regeneration. Developmental Dynamica, vol.226, no. 2, p. 190-201.

Angus, R. A. and Peoples, S. D.(2001). Gonopodium development in normal male and 11- Ketotestosterone treated female Mosquitofish (Gambusia affinis) : A quantitative study using computer image analysis. Endo. Vol. 123, Issue 2, p. 222-234.

Arita, G. S.(1971). Are-examination of the functional morphology of the soft-rays in teleosts. Copeia, vol. no.4, p. 691-697.

Atta, k. I.; Abdel-Karim, A. E. and Elsheikh, E. H.(2012). Ultrastructural study of the effect of heavy metals on the regenerating tail fin of the teleost fish, Oreochromis niloticus . J. Basi. Appl. Zool. 65,232-239.

Baruš, V.; Oliva, O. (eds) et al.,(1995). Mihulovci Petromyzontes a Ryby Osteichthyes (1). Fauna ĞR a Sr. Praha; Academia , 624pp. ISSN 0430-120X.

Becerra, J. ; Montes, G. S. ; Bexiga, S.R.R. and Junqueiram, L. C.U.(1983). Structure of the tail fin in teleosts. Cell and Tissue Research, vol. 230,no. 1, p. 127- 137.

Bechara, I. J.; Böckelmann, P. K.; Montes, G. S. and Cruz-Höfling, M. A.(2003). Inhibition of caudal fin actinotrichia regeneration by acetylsalicylic acid (ASPIRIN) in teleosts. Braz. J. Morphol. Sci.20(2): 67-74.

Bechara, I. J.; Joazeiro, P.P.; Marí-Beffa, M.; Becerra, J. and Montes, G. S.(2000). Collagen-affecting drugs impair regeneration of teleost tail fins. J. Sub. Cyt. and Path., vol. 32, no. 2, p. 273-280. PMid; 11085216.

Darias, M. J.; Lan Chow Wing, O.; Cahu, C.; Zambonion - Infante, J. L. and Mazurais, D.(2010). J. App. Ichth. Vol. 26 , Issue 2, p.280-285.

Drucker, E. G. and Lauderm G. V.(2003). Function of pectoral fins in rainbow trout : behavioral repertoire and hydrodynamic forces. J. Exp. Biol.206 (5):813-826. ISSN 0022-0949.

Fitzpatrick, L. A.(2006). Estrogen therapy for postmenopausal osteoporosis. Arq. Bras. Endo. Meta. 50:705-719.

Fricke, R.(1981a). The Kaianus- group of the genus (Pisces; Callionymidae), with descriptions of six new species Proc. California Acad. Sci., 42(14):349- 377.

Fricke, R.(1981b). Revision of the genus Synchiropus (Teleostei: Callionymidae). Theses Zoologicae, 1, Braunschweig : 194pp.

Fricke, R.(1983c). A method for Counting Caudal Fin Rays of Actinopterygian Fish. Braunschw. Naturk. Schr. 1. Heft 4: 729-733.

Ginsburg, I.(1945). Contribution to a methodology in the caudal fin count of fishes and its use in classification. Copeia,(3): 133-142, tabs. 1-3.

Gupta, A.; Jain, G. K. and Raghubir, R.(1999). A time course study for the development of an immunocompromised wound model, using hydrocortisone. J. Phar. And Toxi. Meth. Vol. 41, no. 4, p. 183187.

Hofbauer, LC.(1999). Osteoprotegerin ligand and osteoprotegerin : novel implications for osteoclast biology and bone metabolism. Eur. J. Endocrinol.,141:195-210.

Humason, G. L.(1972). Animal tissue techniques. $3^{\text {rd }}$ ed. W. h. Freeman and Company, son fran- $614 p$.

huso Linnaeus, 1758) in estuaries of the Caspian Sea. Inter. J. Aqua. Bio.3(3):129-134.

Johnson, S.L. and Bennett, P.(1999). Growth Control in the Ontogenetic and Regenerating Zebrafish fin.Meth. In C. Bio. Vol,59.

Kawashima, H.; Ogose, A.; Hayami, T.;Yamagiwa, H.; Hatano, H.;Hotta. T. and Endo, N.(2003). Effect of dexamethasone on growth inhibition and chondrogenic maturation of human chondrosarcoma. Journal of Orthopaedic Science, Vol.8, no. 3, p.341-345.

Kim, HJ.; Zhao, H.; Kitaura, H. and et al.(2006). Glucocorticoids suppress bone formation via the osteoclast. J. 
Clin. Invest., 116:2152-2160.

Krukenber, G. CF.(1985). Über die chemische Beschaffenheit der sog. Hornfaden von Muste lus und uber die Zusammensetzung der Keratinosen Hollen um die Eier von Scyllium stellate . Mitt Zool Stat Ne aple, vol. 6 p.286- 296.

Kumar, S.; Behera, S.; Nagesh, T. S. ; Gogoi, R. and Prakash, B.(2016). Effect of 17 $\alpha$ - Methyltestosterone on the growth performance of a fighting fish (Betta Splendens). J. Exp. Zoll. India vol. 19, no. 1, pp. 89-93.

Lauder, G. V. and Drucker, E. G.(2004). Morphology and experimental hydrodynamics of fish fin control surfaces. IEEE J. Oceanic Eng. 29, 3: 556-571. ISSN 0364-9059.

Lauder, G. V.(2006).Chapter 1 Locomotion, pp.3-46. In: EVANS, D. H. AND CLAIBORNE, J. B. (eds): The physiology of fishes, third edition. Boca Raton; CRC Press Taylor and Francis Group, 601pp. ISBN $084932022497 ; 80849320224$.

Liu, L.; Porta, A.; Peng, X. and et al.(2004). Prevention of glucocorticoid induced apoptosis in osteocytes and osteoblasts by calbindin D28k. J. Bone Miner Res., 19:479-490.

Mabee, PM.; Crotwell, PL.; Bird, NC. And Burke, AC.(2002). Evolution of median fin modules in the axial skeleton of fishes. The Journal of Experimental Zoology, vol.294, no. 2,p. 77-90.

Manelli, PM.; Crotwell, PL.; Bird, NC. and Burke, AC.(2002). Evolution of median fin modules in the axial skeleton of fishes. The Journal of Experimental Zoology, Vol.294, no. 2, p.77-90.

Mazloumi, N.; Amiri, B. M.; Nematollahi, M. and Rafieem G.(2015). Hydrocortisone treatment may enhance survival and stocking of Beluga sturgeon (Huso

Ochandio, B. S.; Bechara, I. J. and Parise-Maltempi, P.P.(2015). Dexamethasone action on caudal fin regeneration of carp Cyprinus carpio (Linnaeus, 1758). Braz. J. Biol. Vol. 75, no. 2,p. 442-450.

Oishi, Y.; FU, ZW.; Ohnuki, Y.; Kato, H. and Noguchi,T. (2002). Molecular basis of the alteration in skin collagen metabolism in response to in vivo dexamethasone treatment : effects on the synthesis of collagen type I and III, collagenase, and tissue inhibitors of metalloproteinases. The British Journal of Dermatology, Vol.147, no.5, p.859-868.

Sfakiotakis, M.; Lane, DM. and Davies, JBC.(1999). Review of fish swimming modes for aquatic locomotion. IEEE Journal of Oceanic Engineering, 24(2): 237- 252.

Spurny, P.(1998). Icthyologie: (obecaná část). 1. vyd. Brno: Mendelova zemědělská a lesnická univerzita v Brně,138pp. ISBN 80-7157-341-8.

Talas, D. U. ; Nayci, A.; Atis, S.; Polat, A.; Comelekoglu, U.; Bagdatoglu, C. and Renda, N.(2002). The effects of corticosteroids on healing of tracheal anastomoses in a rat model. Pharmacological Research: The Official J. Ital. Phar. Soci. Vol. 45, no. 4, p. 299-304.

Tenius, FP.; Biondo-Simoes, MLP. and Ioshi,SO.(2007). Efeitos do uso crônico da dexametasona na cicatrização de feridas cutâneas em ratos. Brazilian Annals of Dermatology, Vol.82, no.2.

Tolar, J.; Teitelbaum, S. L. and Orchard, P. J.(2004).Osteopetrosis. N. Engl. J. Med.351: 2839-2849.

Weinstein, RS.; Chen, JR.; Powers, CC. and et al.(2002). Promotion of osteoclast survival and antagonism of bisphosphonate- induced osteoclast apoptosis by glucocorticoids. J. Clin. Invest.,109:1041-1048.

Zodrow, JM. and Tanguay, RL. (2003). 2,3,7,8- tetrachlorodibenzop- dioxin inhibits zebrafish caudal fin regeneration. Toxicological Sciences : An Official Journal of The Society of Toxicology, Vol.76, no. 1, p. 151-161. 